\title{
Transdermal fentanyl patch for postoperative analgesia in total knee arthroplasty: a randomized double-blind controlled trial
}

This article was published in the following Dove Press journal:

Journal of Pain Research

I August 2014

Number of times this article has been viewed

\author{
Thepakorn \\ Sathitkarnmanee' \\ Sirirat Tribuddharat ${ }^{1}$ \\ Kanlayarat Noiphitak ${ }^{2}$ \\ Sunchai Theerapongpakdee \\ Sasiwimon Pongjanyakul' \\ Yuwadee Huntula' \\ Maneerat Thananun' \\ 'Department of Anesthesiology, \\ Faculty of Medicine, Khon Kaen \\ University, Khon Kaen, ${ }^{2}$ Chulabhorn \\ Hospital, Bangkok, Thailand
}

Purpose: To assess the efficacy of a transdermal fentanyl patch (TFP) (50 $\mu \mathrm{g} / \mathrm{hour})$ applied 10-12 hours before surgery versus placebo for postoperative pain control of total knee arthroplasty (TKA).

Materials and methods: We enrolled 40 patients undergoing elective TKA under spinal anesthesia using isobaric or hyperbaric bupivacaine. Subjects were randomized to receive a TFP (Duragesic ${ }^{\circledR} 50 \mu \mathrm{g} /$ hour) or placebo patch applied with a self-adhesive to the anterior chest wall 10-12 hours before spinal anesthesia. Every patient was given patient-controlled morphine for postoperative pain control. Patients were evaluated every 4 hours until 48 hours.

Results: Morphine consumption at 24 and 48 hours in the TFP group versus the placebo group was $15.40 \pm 12.65$ and $24.90 \pm 20.11 \mathrm{mg}$ versus $33.60 \pm 19.06$ and $57.80 \pm 12.65 \mathrm{mg}(P \leq 0.001)$. Numeric rating scale scores at rest and during movement over 48 hours were lower in the TFP group. Ambulation and nausea/vomiting scores were statistically greater, but not clinically significant in the TFP group. Sedation scores were low and not statistically significantly different between groups. There was no severe respiratory depression.

Conclusion: TFP (50 $\mu \mathrm{g}$ /hour) applied 10-12 hours before surgery can effectively and safely decrease morphine consumption and pain scores during the first 48 hours after TKA surgery.

Keywords: analgesia, total knee arthroplasty, fentanyl, matrix transdermal delivery system, patient-controlled analgesia

\section{Introduction}

Total knee arthroplasty (TKA) is a surgery that improves patient mobility and quality of life, but causes severe postoperative pain during the first 24-72 hours. ${ }^{1}$ Adequate postoperative pain control promotes patient ambulation and physiotherapy, ${ }^{2}$ leading to early recovery, fewer complications (ie, deep-vein thrombosis or nosocomial infection), and a shorter hospital stay. ${ }^{3}$ There are many methods for relieving postoperative pain in TKA, including patient-controlled analgesia (PCA), ${ }^{4}$ patient-controlled epidural analgesia, ${ }^{4}$ spinal morphine, ${ }^{5}$ femoral nerve block, ${ }^{3}$ and continuous posterior lumbar plexus block. ${ }^{6}$ These methods, however, require personal skills and expensive equipment.

The transdermal fentanyl patch (TFP) is a skin-patch opioid that steadily releases fentanyl into the bloodstream according to the dosage applied. ${ }^{7}$ The subsequent plasma level and clearance are similar to intravenous use. ${ }^{8}$ TFPs are commonly used for chronic pain management. ${ }^{9,10}$ Typically, a TFP has a slow onset (plateauing in 15 hours), which makes it inappropriate for acute pain control. ${ }^{11-13}$ If, however, it is applied 12-14 hours before surgery, it may effectively relieve postoperative pain in TKA.

\section{Sathitkarnmanee}

Department of Anesthesiology, Faculty of Medicine, Khon Kaen University, 123 Moo 16 Mittraphap Road, Tambon Muang, Khon Kaen 40002, Thailand Tel +66 8I 9547622

Fax +66 43348390

Email thepakorns@gmail.com 
Our hypothesis was that a TFP (50 $\mu \mathrm{g} /$ hour) applied 10-12 hours before surgery would provide superior analgesia for 48 hours compared with placebo for postoperative pain control in TKA. The primary outcome was a difference in cumulative morphine consumption at 48 hours after surgery.

\section{Materials and methods}

The current study was approved by the Institutional Review Board of Khon Kaen University (HE521183) and registered at www.clinicaltrials.gov (NCT01348984). Written informed consent was obtained from all subjects.

Our study was a prospective randomized double-blind controlled trial. Using Minville et $\mathrm{a}^{14}$ as a guide, we determined that for an $\alpha$-value of 0.05 and a power $(1-\beta)$ of 0.80 , the sample size needed to be 19 patients in each group. We recruited 40 patients to cover dropout. Randomization was achieved using a computer-generated list kept in sealed opaque envelopes. We included patients between 20 and 80 years of age, scheduled for elective TKA under spinal anesthesia, having an American Society of Anesthesiologists (ASA) physical status of I-II, and able to use a PCA. We excluded patients who: 1) were pregnant or breastfeeding, 2) had a history of allergy to TFPs or morphine, 3) had a contraindication for spinal anesthesia, 4) had major organ diseases, and 5) had a history of drug abuse.

The patients, admitted 1 day prior to the surgery, were then allocated to two groups: group $\mathrm{T}$ received a single TFP (Duragesic ${ }^{\circledR} 50 \mu \mathrm{g} /$ hour matrix fentanyl patch; Janssen Pharmaceutica, Beerse, Belgium) affixed to the anterior chest wall 10-12 hours before surgery by the preoperativevisit resident; and group P received a placebo patch in the same manner. Spinal anesthesia was given using either hyperbaric or isobaric bupivacaine at a standard dosage. All of the patients received standard intraoperative monitoring and care. After surgery, they were transferred to the postanesthetic care unit. Time of arrival at the unit represented time 0 . The severity of pain was determined using a numeric rating scale (NRS). PCA was started after the NRS had fallen to $\leq 3$ in response to intravenous morphine supplementation (at $2 \mathrm{mg} / 5$ minute intervals). The PCA device was set at $1 \mathrm{mg}$ of morphine with a 5-minute lockout and a 1-hour limit of $8 \mathrm{mg}$. Every 4 hours until 48 hours, we recorded morphine consumption, blood pressure, respiratory rate, NRS score at rest and when moving, ambulation, sedation, and nausea/ vomiting (N/V) score. The TFP was removed at 48 hours (Figure 1).

Ambulation scoring was $0=$ unable to sit up in bed, $1=$ able to sit up in bed, $2=$ able to sit on the edge of the bed with feet hanging down over the side, and $3=$ able to move from bed to a chair with assistance. Sedation scoring was $0=$ fully alert, $1=$ mild sedation, easy to rouse, $2=$ moderate sedation, arousable with gentle shaking, and $3=$ deep sedation, not aroused by speaking or gentle shaking. N/V scores were $0=$ none, $1=$ mild, $2=$ moderate, and $3=$ severe. We noted all adverse effects and postoperative complications, such as itching and severe respiratory depression (respiration rate $\leq 8$ breaths/minute).

Statistical analyses were performed using SPSS 17.0 for Windows (SPSS, Chicago, IL, USA). Continuous data are presented as mean (standard deviation) and categorical data as $\mathrm{n}(\%)$. To compare the differences between groups, Student's $t$-test, $\chi^{2}$ test, or analysis of variance was used as applicable. $P<0.05$ was considered statistically significant.

\section{Results}

A total of 40 patients completed the study. The demographic data and anesthetic time for both groups were comparable (Table 1). Compared to the placebo, the TFP significantly reduced cumulative morphine consumption over 24 and 48 hours by $54.2 \%$ and $56.9 \%$, respectively (ie, 18.2 and $32.9 \mathrm{mg}$; Table 2 and Figure 2). The average NRS scores at rest and during joint movement over the 48 hours were significantly lower in group $\mathrm{T}$ (Figure 3 ). In addition, ambulation scores over 48 hours were significantly higher in group T. Sedation scores over 48 hours were not significantly different between the groups. N/V scores over 48 hours were significantly higher in group $\mathrm{T}$ (Table 2 ). There was no severe respiratory depression.

\section{Discussion}

Our study demonstrates that a TFP (50 $\mu \mathrm{g} /$ hour) applied 10-12 hours before surgery can safely relieve postoperative pain from TKA for 48 hours. Over 24 and 48 hours, the TFP reduced morphine consumption by $54.2 \%$ and $56.9 \%$, respectively. Importantly, NRS scores were lower both at rest and during movement, with comparable low sedation scores. Although ambulation and N/V scores were statistically different, there was no clinical significance, as both scores were lower than 1 .

The results of the present study are in accord with previous studies in which TFPs provided dose-dependent analgesia after lower abdominal surgery. ${ }^{15}$ A TFP administering $75 \mu \mathrm{g} /$ hour is also used as a safe and effective analgesic after major shoulder surgery. ${ }^{16}$ Other studies showed that TFPs can safely reduce morphine consumption and pain scores for patients undergoing hemorrhoidectomy, ${ }^{17}$ major urological 


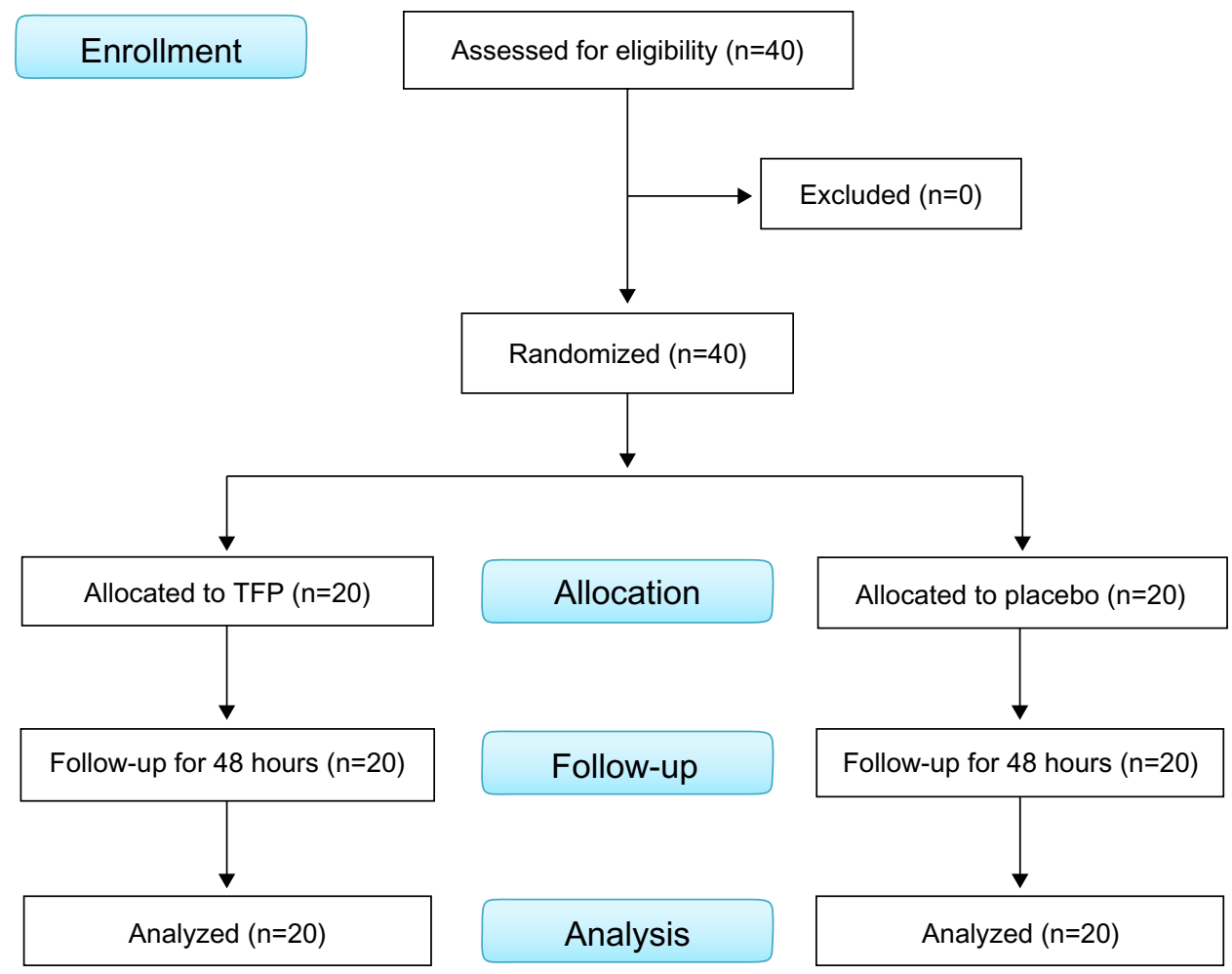

Figure I Flowchart for patient recruitment, randomization, and follow-up.

Abbreviation: TFP, transdermal fentanyl patch.

operations, ${ }^{18}$ abdominal surgery, ${ }^{19}$ and total hip arthroplasty. ${ }^{14}$ By contrast, some studies have reported that TFPs did not significantly relieve postoperative pain. ${ }^{20,21}$ In the latter, the TFP was placed just before or within 2 hours of surgery. For TFPs to be effective, its serum level must plateau (ie, 15 hours after being affixed), which would be before the end of surgery. ${ }^{13}$ Osipova et al studied the effect of TFPs for prevention and treatment of postoperative pain syndrome in extensive thoracoabdominal oncological surgery, and concluded that TFPs in the early postoperative period may prevent acute opioid tolerance and hyperalgesia, underscoring the benefit of their

Table I Demographic and operative data

\begin{tabular}{lll}
\hline & $\begin{array}{l}\text { Group T } \\
(\mathbf{n = 2 0 )}\end{array}$ & $\begin{array}{l}\text { Group P } \\
(\mathbf{n}=\mathbf{2 0})\end{array}$ \\
\hline Age (years) & $64.90(7.3 \mathrm{I})$ & $66.20(8.48)$ \\
Sex (male) & $17(85 \%)$ & $19(95 \%)$ \\
ASA physical status (I:II) & $20: 0$ & $15: 5$ \\
Weight $(\mathrm{kg})$ & $66.65(7.54)$ & $63.05(9.46)$ \\
Height $(\mathrm{cm})$ & $155.35(5.57)$ & $153.40(5.45)$ \\
BMI $\left(\mathrm{kg} / \mathrm{m}^{2}\right)$ & $27.64(3.10)$ & $26.88(4.45)$ \\
Anesthetic time (minutes) & $168.50(54.65)$ & $159.00(40.3 \mathrm{I})$ \\
\hline
\end{tabular}

Notes: Group T patients received a transdermal fentanyl patch; group P patients received placebo. Data for age, weight, height, BMI, and anesthetic time are presented as means (standard deviation).

Abbreviations: ASA, American Society of Anesthesiologists; BMI, body mass index. use in multimodal postoperative analgesia with nonsteroidal anti-inflammatory drugs (NSAIDs). ${ }^{22}$

Although we did not encounter any severe respiratory depression, this may have been due to the small sample size, as in other studies. ${ }^{14-19}$ The adverse effects of TFPs are dosedependent, as with other narcotic administration. Sedation scores do not increase, albeit reductions in the respiratory rate rise, with doses up to $75 \mu \mathrm{g} /$ hour. ${ }^{15,16,23}$ We concur with Bulow et al that a TFP administering $100 \mu \mathrm{g} /$ hour would be too potent, because of the potential for life-threatening respiratory depression. ${ }^{24}$ For patient safety, we chose the lower dosage, ie, $50 \mu \mathrm{g} /$ hour, for our study. Nevertheless, Cole et al reported that variability of TFP metabolism and excretion in pain patients contributed to unpredictable adverse effects. ${ }^{25}$ In a review, Nelson and Schwaner concluded that close observation by well-trained personnel is needed, due to serious adverse effects from unintentional misuse or even in normal use. ${ }^{26}$ In cases of severe bradypnea, naloxone can be used to treat the symptoms promptly. ${ }^{27}$ Since the duration of TFPs is much longer than naloxone, one dose of naloxone may be insufficient, and a continuous infusion may be needed.

The TFP has many advantages: it can easily adhere to the skin, obviating an intravenous line, so there is little 
Table 2 Morphine consumption and NRS, ambulation, sedation, and N/V scores

\begin{tabular}{|c|c|c|c|c|c|}
\hline & Group T $(n=20)$ & Group P $(n=20)$ & Mean difference & $95 \% \mathrm{Cl}$ & $P$-value \\
\hline Morphine consumption in 24 hours (mg) & $15.40(12.65)$ & $33.60(19.06)$ & -18.20 & -28.55 to -7.85 & 0.001 \\
\hline Morphine consumption in 48 hours (mg) & $24.90(20.11)$ & $57.80(28.70)$ & -32.90 & -48.76 to -17.04 & $<0.001$ \\
\hline NRS score at rest & $2.73(1.95)$ & $4.64(1.60)$ & -1.91 & -3.05 to -0.77 & 0.002 \\
\hline NRS score during movement & $4.39(2.37)$ & $6.42(1.40)$ & -2.02 & -3.27 to -0.78 & 0.002 \\
\hline Ambulation score & $0.60(0.18)$ & $0.44(0.23)$ & 0.15 & 0.02 to 0.29 & 0.026 \\
\hline Sedation score & $0.27(0.29)$ & $0.18(0.23)$ & 0.09 & -0.08 to 0.25 & 0.299 \\
\hline N/V score & $0.59(0.44)$ & $0.31(0.38)$ & 0.29 & 0.02 to 0.55 & 0.033 \\
\hline
\end{tabular}

Notes: Group T patients received a transdermal fentanyl patch; group P patients received placebo. Data presented as means (standard deviation).

Abbreviations: $\mathrm{Cl}$, confidence interval; NRS, numeric rating scale; $N / V$, nausea/vomiting.

risk of infection, it is easily procured and costs less than a PCA pump, and it needs no programming, so no human error occurs. ${ }^{14}$ It may be a good alternative in acute pain management.

\section{Limitations of the study}

Despite our using safer TFP dosing ( $50 \mu \mathrm{g} /$ hour), the sample size of the study was limited, so we cannot conclude that there is no danger of severe respiratory depression. As our inclusion criteria included an ASA physical status of I-II and since these patients very often had an ASA physical status of III, we cannot conclude whether the TFP is suitable for use in these patients. Similarly, we cannot conclude whether or not TFPs would be effective for other major surgeries either. Further studies with larger sample sizes are needed to address these issues.
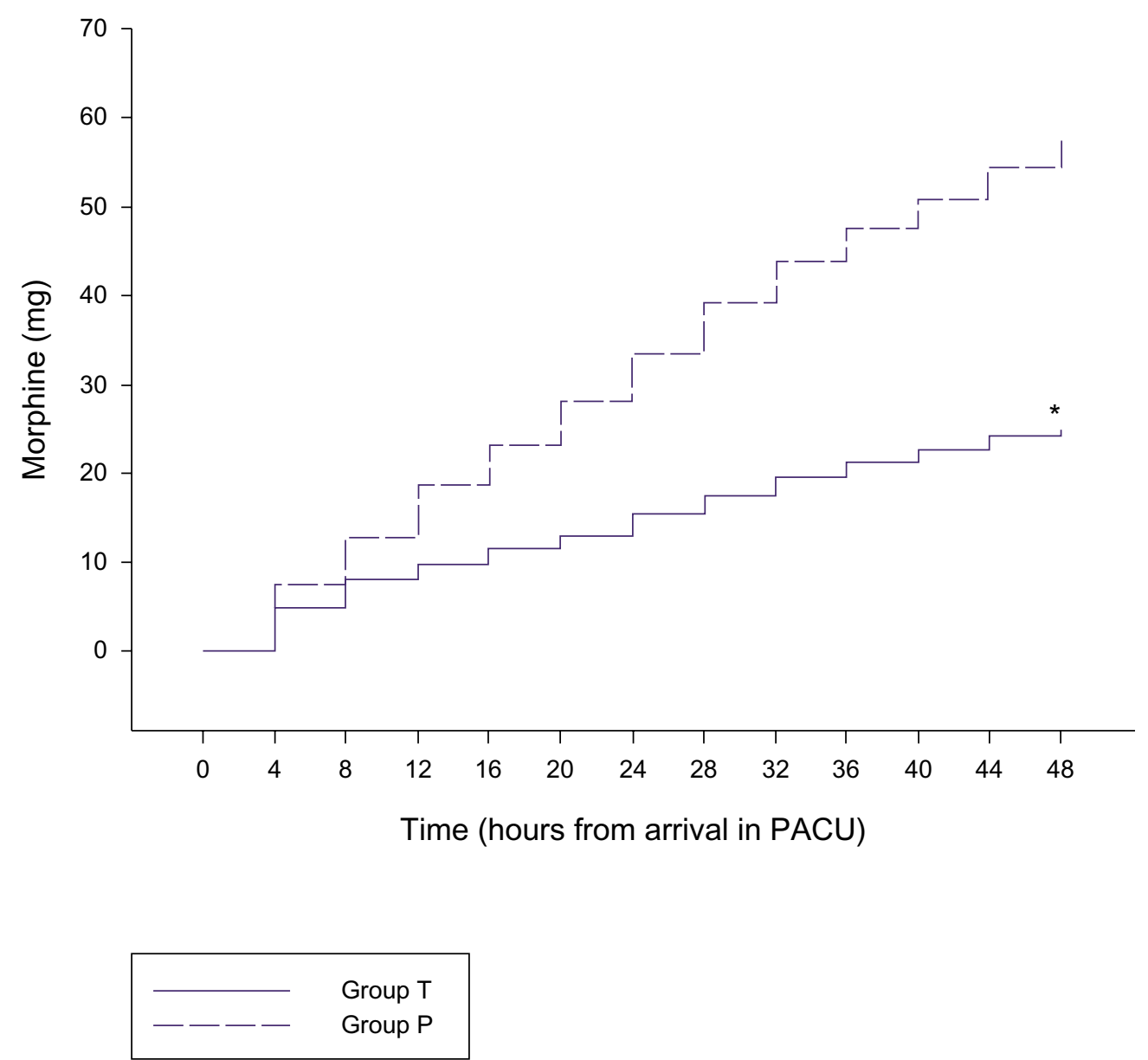

Figure 2 Cumulative morphine consumption over 48 hours.

Notes: $* P \leq 0.001$. Group $T$ patients received a transdermal fentanyl patch; group $\mathrm{P}$ patients received placebo.

Abbreviation: PACU, postanesthetic care unit. 


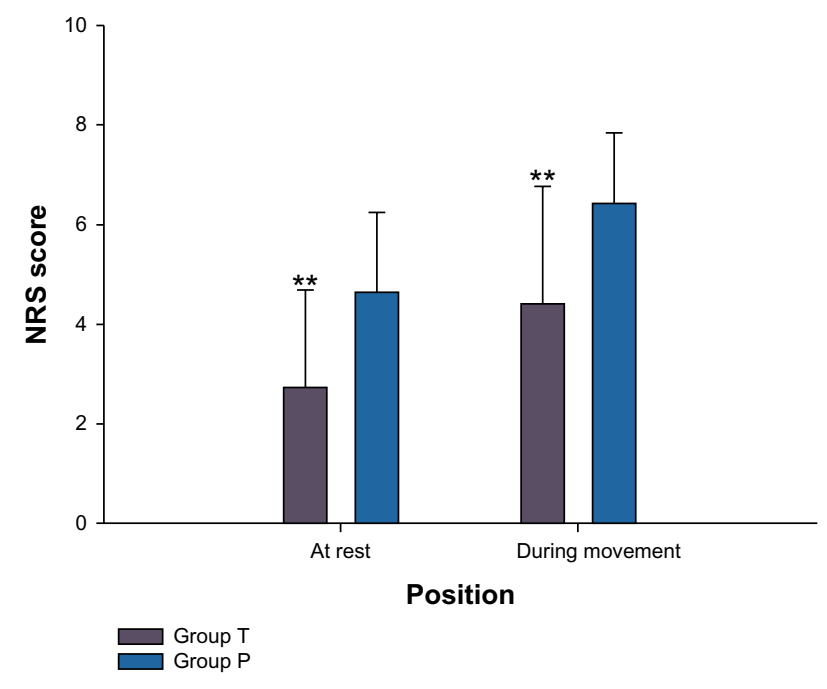

Figure 3 Numeric rating pain score at rest and during movement over 48 hours. Notes: ${ }^{*} P=0.002$. Group $T$ patients received a transdermal fentanyl patch; group $P$ patients received placebo. Data presented as means (standard deviation).

Abbreviation: NRS, numeric rating scale.

\section{Conclusion}

A TFP (50 $\mu \mathrm{g} /$ hour) applied 10-12 hours before surgery can be used as a postoperative analgesic for TKA, and can reduce morphine consumption over 48 hours by more than $55 \%$ without serious complications. The patients were more comfortable, and this was evidenced by lower pain scores both at rest and during movement. TFPs, we propose, may be effectively used in multimodal mode, in conjunction with other moderate analgesics (eg, NSAIDs) in accordance with the World Health Organization pain ladder. ${ }^{28}$ Severe bradypnea may however occur as a result of any route of narcotic administration, so close monitoring by well-trained personnel - having naloxone close at hand in the event of severe respiratory depression - is recommended.

\section{Acknowledgments}

This study was supported by the Faculty of Medicine, Khon Kaen University. We thank the patients and their families for their participation, the hospital pharmacy staff for their assistance, the nursing staff for their coordination, and Mr Bryan Roderick Hamman and Mrs Janice LoewenHamman for assistance with the English language presentation of the manuscript.

\section{Disclosure}

The authors report no conflicts of interest in this work.

\section{References}

1. Allen JG, Denny NM, Oakman N. Postoperative analgesia following total knee arthroplasty: a study comparing spinal anesthesia and combined sciatic femoral 3-in-1 block. Reg Anesth Pain Med. 1998;23(2):142-146.
2. Choi PT, Bhandari M, Scott J, Douketis J. Epidural analgesia for pain relief following hip or knee replacement. Cochrane Database Syst Rev. 2003;(3):CD003071.

3. Paul JE, Arya A, Hurlburt L, et al. Femoral nerve block improves analgesia outcomes after total knee arthroplasty: a meta-analysis of randomized controlled trials. Anesthesiology. 2010;113(5): $1144-1162$.

4. Bertini L, Tagariello V, Molino FM, Posteraro CM, Mancini S, Rossignoli L. [Patient-controlled postoperative analgesia in orthopedic surgery: epidural PCA versus intravenous PCA]. Minerva Anestesiol. 1995;61(7-8):319-328. Italian.

5. Frassanito L, Vergari A, Zanghi F, Messina A, Bitondo M, Antonelli M. Post-operative analgesia following total knee arthroplasty: comparison of low-dose intrathecal morphine and single-shot ultrasound-guided femoral nerve block: a randomized, single blinded, controlled study. Eur Rev Med Pharmacol Sci. 2010;14(7):589-596.

6. Kaloul I, Guay J, Côté C, Fallaha M. The posterior lumbar plexus (psoas compartment) block and the three-in-one femoral nerve block provide similar postoperative analgesia after total knee replacement. Can J Anaesth. 2004;51(1):45-51.

7. Thompson JP, Bower S, Liddle AM, Rowbotham DJ. Perioperative pharmacokinetics of transdermal fentanyl in elderly and young adult patients. Br J Anaesth. 1998;81(2):152-154.

8. Duthie DJ, Rowbotham DJ, Wyld R, Henderson PD, Nimmo WS. Plasma fentanyl concentrations during transdermal delivery of fentanyl to surgical patients. Br J Anaesth. 1988;60(6):614-618.

9. Kornick CA, Santiago-Palma J, Khojainova N, Primavera LH, Payne R, Manfredi PL. A safe and effective method for converting cancer patients from intravenous to transdermal fentanyl. Cancer. 2001;92(12):3056-3061.

10. Kornick CA, Santiago-Palma J, Moryl N, Payne R, Obbens EA. Benefitrisk assessment of transdermal fentanyl for the treatment of chronic pain. Drug Saf. 2003;26(13):951-973.

11. Holley FO, van Steennis C. Postoperative analgesia with fentanyl: pharmacokinetics and pharmacodynamics of constant-rate iv and transdermal delivery. Br J Anaesth. 1988;60(6):608-613.

12. Estève M. [Transcutaneous fentanyl]. Cah Anesthesiol. 1994;42(2): 195-217. French.

13. Grond S, Radbruch L, Lehmann KA. Clinical pharmacokinetics of transdermal opioids: focus on transdermal fentanyl. Clin Pharmacokinet. 2000;38(1):59-89.

14. Minville V, Lubrano V, Bounes V, et al. Postoperative analgesia after total hip arthroplasty: patient-controlled analgesia versus transdermal fentanyl patch. J Clin Anesth. 2008;20(4):280-283.

15. Broome IJ, Wright BM, Bower S, Reilly CS. Postoperative analgesia with transdermal fentanyl following lower abdominal surgery. Anaesthesia. 1995;50(4):300-303.

16. Caplan RA, Ready LB, Oden RV, Matsen FA 3rd, Nessly ML, Olsson GL. Transdermal fentanyl for postoperative pain management. A double-blind placebo study. JAMA. 1989;261(7): 1036-1039.

17. Kilbride M, Morse M, Senagore A. Transdermal fentanyl improves management of postoperative hemorrhoidectomy pain. Dis Colon Rectum. 1994;37(11):1070-1072.

18. Lehmann KA, Einnolf C, Eberlein HJ, Nagel R. Transdermal fentanyl for the treatment of pain after major urological operations. A randomized double-blind comparison with placebo using intravenous patient-controlled analgesia. Eur J Clin Pharmacol. 1991;41(1): $17-21$.

19. Lehmann LJ, DeSio JM, Radvany T, Bikhazi GB. Transdermal fentanyl in postoperative pain. Reg Anesth. 1997;22(1):24-28.

20. Sevarino FB, Naulty JS, Sinatra R, et al. Transdermal fentanyl for postoperative pain management in patients recovering from abdominal gynecologic surgery. Anesthesiology. 1992;77(3):463-466.

21. Rowbotham DJ, Wyld R, Peacock JE, Duthie DJ, Nimmo WS Transdermal fentanyl for the relief of pain after upper abdominal surgery. Br J Anaesth. 1989;63(1):56-59. 
22. Osipova NA, Petrova VV, Lastukhin AV, Kudriavtsev SB, Vashakmadze LA, Khomiakov VM. [Prevention and treatment of postoperative pain syndrome in extensive thoracoabdominal oncological surgery]. Anesteziol Reanimatol. 2010;(3):29-33. Russian.

23. Sandler AN, Baxter AD, Katz J, et al. A double-blind, placebocontrolled trial of transdermal fentanyl after abdominal hysterectomy. Analgesic, respiratory, and pharmacokinetic effects. Anesthesiology. 1994;81(5):1169-1180.

24. Bulow HH, Linnemann M, Berg H, Lang-Jensen T, LaCour S, Jonsson T. Respiratory changes during treatment of postoperative pain with high dose transdermal fentanyl. Acta Anaesthesiol Scand. 1995;39(6): 835-839.
25. Cole JM, Best BM, Pesce AJ. Variability of transdermal fentanyl metabolism and excretion in pain patients. J Opioid Manag. 2010;6(1): 29-39.

26. Nelson L, Schwaner R. Transdermal fentanyl: pharmacology and toxicology. J Med Toxicol. 2009;5(4):230-241.

27. van Bastelaere M, Rolly G, Abdullah NM. Postoperative analgesia and plasma levels after transdermal fentanyl for orthopedic surgery: double-blind comparison with placebo. J Clin Anesth. 1995;7(10): 26-30.

28. World Health Organization. WHO's cancer pain ladder for adults. 2009. Avaialble from: http://www.who.int/cancer/palliative/painladder/en. Accessed July 2, 2014.

\section{Publish your work in this journal}

The Journal of Pain Research is an international, peer-reviewed, open access, online journal that welcomes laboratory and clinical findings in the fields of pain research and the prevention and management of pain. Original research, reviews, symposium reports, hypothesis formation and commentaries are all considered for publication.

\section{Dovepress}

The manuscript management system is completely online and includes a very quick and fair peer-review system, which is all easy to use. Visit http://www.dovepress.com/testimonials.php to read real quotes from published authors. 